\title{
'65 year old man rapes, impregnates own teenage daughter': Rape Representation in Two Nigeria Newspapers
}

\section{Oludayo Tade Collins Udechukwu}

Department of Sociology

University of Ibadan, Ibadan, Nigeria

DOI:10.36108/NJSA/8102/61(0230)

\begin{abstract}
Rape of females in Nigeria has reached a disturbing proportion. While the media has played a major role in creating awareness about rape, their representations of rape are crucial in determining post-rape responses. This study, therefore investigates newspaper coverage and representations of rape in two select newspapers in Nigeria (2012-2016). It utilizes two national dailies (The Punch and The Sun) with dedicated crime pages to understand the frequency of reportage, factors underlying low or nonreportage of rape by victims, and the dominant frame used in reporting rape. Findings show that 331 cases of rape were reported within the period with southwestern part of the country recording largest occurrence. Low or non-reporting behavior of rape by victims was affected by fear of stigma, fear of the rapist due to threats, religious sentiments, family interventions, and inability to access the media. The dominant frame utilized in reporting rape was human interest frame. The paper recommends diagnostic and prognostic frames to attract informed policies and give justice to the raped.
\end{abstract}

\section{Introduction}

Unlawful carnal knowledge against girls and women has become a recurring social problem in Nigeria. Rape which implies sexual knowledge without the consent of the female is now ubiquitous across the six geo-political zones in Nigeria. Its occurrence has attracted empirical investigation by scholars who have probed into the failures of laws to protect females from rape in Nigeria (Onyejwe, 2008). Akinade et al. (2010) examined the social and legal factors influencing rape perpetration and the possible characteristics of actors. Daru et al. (2011) conducted a clinical study on improving the care of the victims of rape. They were concerned with the possible implications of contracting HIV/AIDS as outcomes of rape for victims. Chika's (2011) was interested in marital rape unveiling the institutional blockage towards enjoying reproductive rights among Nigerian married women. Buba (2015) conceptualized rape as an instrument of war focusing on how rape is deployed as a strategy by Bokoharam terrorists.

While these studies are unique in their design and focus, they however did not examine rape representations in the media. Traditional media in Nigeria play pivotal role in directing attention to criminal behaviours such as rape. By doing this, the media contributes to policing by inviting formal and informal responses to the reported incidence. Media coverage of rape creates awareness; 
provide data on context of rape and actors involved. These are vital data for doing sociology of deviant behaviour. For instance, one Mrs. Ngozi Ugwu reported that her seven-year old niece was raped by three men, namely, Kazeem Mohammed (40 years old), Tobi Daramola (19 years old) and James Anieskin (19 years old) (Daily Sun Newspaper, Thursday 19th December 2013: 27). A pastor, Emmanuel Mathew, aged 50, who was the then General Overseer of the Choice Bible Church was alleged to have raped three pupils, one was aged nine while the other two were both seven years (Vanguard Newspaper, Friday 25th October 2013: 7). Four men reportedly raped an 11year old hawker in Ibadan by forcing her into an uncompleted building and having her in turns. They also threatened her not to tell anybody and later offered her money but her mother took the case to the police before the perpetrators were arrested by the police (Ajayi, 2017, Vanguard Newspaper, July). Rape could also result in the death of the victim. A 14-year-old Obiamaka Ngozichukwu Orakwe, a Junior Secondary School 3 student was raped to death in her parents' home in Abule-Ado area of Lagos State by miscreants who scaled the fence of her house and took turns to rape her (Usman, 2017, Vanguard Newspaper July 28). While these cases indicate the realness of rape and its traumatic consequences on victims, very little scholarly engagement has been deployed to examine how these cases are (re)presented by the media. Against this background, we analyse newspaper reportage of rape cases in Nigeria. Using the coverage of two national newspapers, we examined the frequency of coverage; regional distribution of rape; and dominant frame deployed in reporting rape.

This paper leans theoretically on social constructionism theory. This theoretical leaning has been used by previous studies (see for instance Clemente and Gabbioneta, 2017). The theory built on the tenets of the symbolic interactionism theory by stating that the society and individual's identity within it are constructed through symbolically created social institutions and social interactions. According to Berger and Luckmann (1966), they opined that "Reality is socially defined. But these definitions are always symbolized that is, concrete individuals and groups often serve as definers of reality" (1966: 116). This thus means that individuals through different social interaction and processes construct their realities and their society rather than the society shaping their behavior. This thus leads to 'habitualization', when consistent actions become routines or habits. These routine habits become institutionalized behaviors which take over the larger society. Thus influential institutions such as the media hold enormous power over society which is referred to as 'roles' by Berger and Luckmann (1966) as they are seen as authority figures in the presentation of information. Therefore, if issues of rape are not constantly reported, better framed or subjectively reported it could have implication on both public perception and social policy. This is because media framing is central to how a criminal act is received, perceived, and dealt with. 


\section{Existing Literature}

Throughout history, cultures around the world have experienced forceful sexual intercourse without the consent of the woman. However, rape is not exclusively a crime committed against women. Anyone can regrettably fall victim of rape or other forms of sexual assault. It can be defined as an unlawful or illicit sexual intercourse or canal knowledge with a woman, girl or lady without her consent (by force, deception or while she is asleep) (legal dictionary, 2014). Rape is such a complex issue because it occurs within the purview of a patriarchal society. Thus under this social milieu, force is seen as a privilege and men used this force to maintain their dominance over the women (O'Toole cited in Hurlbutt: 6). The trauma experienced by rape victims is different from that experienced from any other form of violent crime in the sense that a rape victim loses "the sense of control so necessary to survival and will regain it only after many setbacks, false gains, and unbelievable emotional pain" (Simpson \& Cote 2011: 216). The victim then has to cope with series of personal embarrassment and shame and these could according to Jones "go on for years and has been developed in both children and adults and also for both sexual and physical abused children" (Jones 2010: 348).

Rape has been defined differently by various authors and constitutions. In some cases, culture, norms and tradition can influence what is viewed to be rape or consensual intercourse. It can be defined as an act of having unlawful canal knowledge of the body of a girl, lady or woman. Chapter 30 of the Nigerian Criminal Code deals with the conceptualization of what constitutes rape. This is important for this study as the behavior of the criminal law in relation to an act can explain legality or illegality. Subsection 357 (Criminal Code Act CAP C 38; pp 138) of the Criminal code defines rape as:

'Any person who has unlawful carnal knowledge of a woman or girl, without her consent, or with her consent, if the consent is obtained by force or by means of threats or intimidation of any kind, or by fear of harm, or by means of false and fraudulent representation as to the nature of the act, or in the case of a married woman, by personating her husband, is guilty of an offence which is called rape.'

Sub-section 358 prescribes life imprisonment, with or without caning as punishment for rape in Nigeria. However, little has been achieved in this regard.

In the Northern part of Nigeria, rape is defined under section 282 of the penal code as:

(1) A man is said to commit rape who...has sexual intercourse with a woman in any of the following circumstances: (a) against Her will; (b) obtained by putting her in fear of death or of hurt; (c) With her consent when the man knows that he 
is not her husband and that her consent is given because she believes that he is the Man to whom she is or believes herself to be lawfully married; (d) With or without her consent when she is under fourteen years of age or of unsound mind."

(2) Sexual intercourse by a man with his own wife is not considered as rape, if she has attained to puberty."

The two definitions of rape above show that in Nigeria, the conception of rape is seen as being perpetuated only by men against women and not vice versa. The definitions also do not factor non-penetrative rape such as oral sex and use of objects or other instrument aside from the organs as rape. In the United States, according to the Justice department, rape is conceived penetration no matter how small of the vaginal or anus with any body part or object or oral penetration by a sex organ of another person without the consent of the victim. Violence against women is recognized as a human rights abuse (United Nations, 1993) and every country is faced with this challenge on different levels. Therefore, the problem of rape and framing of rape assumes a more complicated dimension especially in a developing country like Nigeria where poor economic background often makes victims more vulnerable and thus resulting in inadequate access to proper health care facilities and security. Despite the fact that rape is a serious and deep-rooted problem in the country, gender violence is still an under-reported crime in Nigeria.

In Nigeria, Rape is growing at an alarming rate. Statistics from the previous years have it that in Lagos alone, 678 cases of rape were reported in 2012, which puts it at an average of two cases per day (Musbau, 2013: 53). Also at least 100 cases of rape were also reported in court in Kano in 2013, in which only about 40 offenders were convicted. Similarly, in Anambra state, about 155 incidences and complaints on rape were recorded by some NGOs that worked on sexual violence in the state, however only 12 out of the 115 cases were taken up by the police and surprisingly none of them was successfully prosecuted (Guardian Newspaper, Friday February 7, 2014: 20). Reasons for the increasing rate of rape in Nigeria according to Oduah (2014: 10) are gaps that are embedded in the laws of the country and the strict adherence by the law court for the provision of burden of proof by the victim and the prosecutors; delays in the judicial system; corruption of the judiciary; stigmatization; family ties; fear of attacks and intimidation and Immoral dressing on the part of the girls and inadequate parental care. Musbau (2013: 53) further noted that rapists were having a jolly ride because the burden of proof lies with the victim. All these occur because of the way rape has been framed both in the criminal code and evidence Act. 
Entman (2007) defines framing as "the process of discarding a few elements of an observed reality and bringing together a story that highlights the connection among them so as to ensure a particular interpretation or reaction". McManus and Dorfman (2002: 6) saw frames as ways of bringing up certain issues for thought. Shen (2004) opined that frames can influence public understanding and interpretation. According to Carlyle et al. (2008: 172), an efficient frame is capable of arousing certain interpretation and reaction by making certain issues noticeable and thus directing attention towards it.

On the effects of frames on public opinion, Carlyle et al. (2008) conducted an investigation to determine newspaper coverage of intimate partner violence in U.S.A. The authors sampled about 395 related newspaper articles for duration of 2 years. Newspaper framing of IPV was greatly dominated by episodic framing. When discussing the implications of such framing, the authors opined that neglecting the underlying causes of IPV and seeing it as a mere individual or relationship issue may predispose victims to public shame and thus blamed for their victimization. To sum up, the authors proposed the provision of contextual features in the coverage of violence against women so as to enable the audience or readers have a full understanding of the story. These contextual features may include: highlighting the relationship that exists between the perpetrator and victim, alcohol use, drug use, presence of weapon etc.

Therefore, Media framing and representation, according to Nwabueze and Oduah (2014) is seen as an artistic creation of the media by giving conspicuous importance to an issue or personality. This is done by making such issues or personalities very important by laying more emphasis on them therefore drawing and focusing the attention of the people in the direction of that issue or personality. Thus the dominant ideas in the media become a trend and yardstick for evaluating wide range of issues (Iyeanger and Reeves, 1997: 213 ). From the foregoing, the amount of attention and prominence given to events, issues or phenomena by the media would go a long way into determining the amount of exposure, knowledge, views, opinion, suggestions and/or criticism given to such issues, events or phenomenon by the people. This shows the importance of regular reportage of rape by the media.

On the role of reportage, Marshall noted that coverage of violence against women especially rape is low despite its high prevalence (Marshall, 2004). Byerly and Ross (2006) further buttress this point in their study of news media in one day across 71 countries where it was evident that women featured less in the news and titles such as victims, mothers and wives were used to depict them. Further, Carter (1998) noted that gender violence has taken new turn over the years from an extraordinary to ordinary news. Carter avers that due to 'hierarchy of news' in which murder is seen as most important and thus takes precedent before rape (Carter, 1998: 223). Gill also noted that rape is rarely 
considered as news except typical cases, often with bizarre or horrific violence. Owing to this, Thorston (in Carlyle et al., 2008: 169) opined that misrepresentation of rape as solely a criminal act when reporting may have severe consequences on health. Therefore, the extent of the coverage of rape as well as its framing can affect the response received by both the public and those in authority or policy makers (Carlyle et al., 2008). Supporting the above assertion Chong and Druckman (2007: 113) argued that whatever is stressed by the media is more likely have the largest effect. This is why it is important to examine media representations of rape reported cases in Nigeria with a view to understanding the frames more dominantly deployed and its implication for action from State and the public.

\section{Methods}

The research was exploratory and was conducted between January through June 2017. It involved the use of the library of the Nigeria Tribune Newspapers in Ibadan where most national newspapers are archived. Nigerian Tribune itself was established in 1949 by the late nationalist, Obafemi Awolowo and played a major role in the nationalist struggle at that time. Two national dailies were purposively selected for their coverage of crime and having dedicated pages for reporting crime. They are The Punch founded in 1971 and The Sun newspapers founded in March 2001. We sorted rape reportage in the papers from January 2012 to December 2016 which covered a period of five years which were purposively selected owing to increasing reportage of rape within this period. Our data emerged from examining the headlines, articles, and news items which captured rape and themes relating to the objectives of the study. The use media reports and media archives have been used by previous studies (see Quarshie et al., 2017; Quarshie, 2017). We found 331 items that were in relation to rape reportage under this period by the two newspapers. These were analysed using content analysis to understand dynamics of reporting and dominant frames used in the reportage of rape.

\section{FINDINGS: Frequency of Rape Coverage in the selected Papers}

The two selected newspapers reported a total of three hundred and thirty-one cases (331). From the table 1, September had the highest number of reported rape cases. On the other hand, December recorded the lowest number of reported rape cases. Furthermore, when the year is split into six months each, the first six months that is from January to June recorded a total of 161 cases as against a total of one hundred and seventy (170) cases recorded for the last six months (that is from August to December). This therefore indicates that the tail end of the year witnessed a higher possibility of rape occurring than the early part of the year. Since rape is an opportunistic crime, the absence of capable guardian may contribute more to rape occurrence. As people focus on money making ahead of festivity, the last quarter of the year, tagged 'ember' months, 
makes a suitable period to execute criminal plans when there is a convergence of suitable target and a willing offender.

Table 1: Frequency of stories on rape reported by the Punch and Daily Sun Newspapers from January 2012 to December 2016

\begin{tabular}{|l|c|c|c|c|c|c|}
\hline Month & $\mathbf{2 0 1 2}$ & $\mathbf{2 0 1 3}$ & $\mathbf{2 0 1 4}$ & $\mathbf{2 0 1 5}$ & $\mathbf{2 0 1 6}$ & Total \\
\hline January & 2 & 1 & 7 & 4 & 4 & 18 \\
\hline February & 4 & 2 & 7 & 4 & 6 & 23 \\
\hline March & 4 & 6 & 8 & 4 & 8 & 30 \\
\hline April & 4 & 9 & 7 & 1 & 12 & 33 \\
\hline May & 4 & 5 & 6 & 5 & 4 & 24 \\
\hline June & 3 & 6 & 9 & 7 & 8 & 33 \\
\hline July & 7 & 9 & 3 & 7 & 7 & 33 \\
\hline August & 5 & 11 & 6 & 8 & 4 & 34 \\
\hline September & 4 & 14 & 3 & 9 & 10 & 40 \\
\hline October & 2 & 5 & 5 & 6 & 5 & 23 \\
\hline November & 1 & 5 & 5 & 4 & 9 & 24 \\
\hline December & 0 & 4 & 4 & 5 & 3 & 16 \\
\hline Total & 40 & 77 & 70 & 64 & 80 & 331 \\
\hline
\end{tabular}

The total number of reported rape cases covered by the newspapers (331) over five-year ${ }^{1}$ period is very low when compared to the rate of rising rape incidents in the country and available cases reported to authorities. Although the media component of rape reporting may be termed externalizing rape in a patriarchal space like Nigeria, we identified factors underlying low reportage of the crime from the narratives of victims and this include:

\section{Stigmatization}

Most times, victims are afraid to speak out because of the way the society may views rape. In most cases victims are seen as socially undesirable and labeled and as such they are blamed for being the reason for their victimisation. When rape victims fear the consequences of revealing what happened to them, they dread being alienated; a case of double jeopardy. This is why most victims would prefer to suffer in silence rather than aggravating the suffering and having no support base. Each time rape occurs, the victim thinks not immediately of herself but the interpretation of the significant others to what happened and how they would treat her. Most times such treatment is negative characterised by de-bonding, isolation, condemnation and alienation. A victim who was interviewed while struggling with the stigma of rape opined that:

\footnotetext{
${ }^{1}$ Certainly the number of those raped within this period is more than that which we covered in this study based on the sampling technique adopted. Again, we may have missed out some few cases in the process of data entry. Nonetheless, the figure gives an outlook of rape as all months phenomenon.
} 
Whenever I think about what happened to me, I feel sad and pained because I can no longer walk freely in the community. People avoid talking to me now in the community. I have become like a leper among my family and people who know me. Nobody would want to marry a girl that has been raped. I hate thinking about the matter. I feel ashamed when I am in the midst of people in the community. (The Punch, Saturday, April 30, 2016: 39)

Our enquiry over the A follow up to the above incidence revealed that the victim above later committed suicide when she could no longer bear the shame.

\section{Fear of the Assailant or Rapist}

Some victims are afraid that the rapist may return if they try to report the incidence to the authorities. In some cases the offender also threatens the victim not to disclose the rape or else they would die. Threats of killing the victim through violence or spiritual attacks instills fear in the victims and make them suffer in silence. It also increases re-victimisation by the same offender. This tends to make victims less inclined to report the incident to the appropriate authorities. An 11-year old girl who was constantly raped by a 78year old man could not voice out due to fear until she mistakenly shouted penis while she was asleep beside her mum. This nightmare was her savior. According to her, she opined that:

I was passing by a shop on our street one Saturday afternoon when I saw him (The suspect). He was sitting outside the shop and told me to help him bring a document inside the shop. I was about to leave after I gave him the document when he dragged me inside and locked the door. He covered my mouth and raped me. He threatened to kill me if I told anybody. I can't remember how many times he had sex with me. Whenever I told him I would tell my mother, he would say I was playing with my life. A few days later my mother said she heard me shout 'penis' while I was asleep. (The Punch, Monday, August 17, 2015: 4-5)

\section{Religion}

There is a spiritual explanation offered to rape incident. Usually, rapists are most times seen as being influenced by evil forces or the devil. An individual is said to be possessed by evil spirit and most of the time needs deliverance. Rape can be an affliction from a perceived enemy to the offender to carry act such as rape which they otherwise would not have done. Thus when a person rapes, the rapist is taken to a Pastor or Imam for exorcism and preached too, thus settling the issue with little or no regards for the victim and as such it's not reported. A 12- year old girl who was raped by her aunt's customer was able to talk after 
her neighbours reported the incidence instead of her aunt who rather took the suspect to her Pastor and closed the case. Narrating the incident, the girl opined that:

When my aunty came back, I told her what happened and she saw that I was still bleeding. She told me to go and clean up the blood. She then went out to go and see the man who raped me. She asked the man what happened and they went to see their pastor together. When they got to the Pastor, Nse (suspect) admitted that he indeed raped me and rather than report to the appropriate authorities, The Pastor, Mr. Ezekiel Okon, asked Nse to kneel as he prayed fervently for him, asking God to deliver him from the spirit of rape. (The Punch, Saturday, April 2, 2016: 47)

\section{Family Ties}

Rape does not get to the media because of the intervention of the family or relatives. This happens most of the time when a family member rapes another family member. Rather than think about justice from the perspective of the victim, they think about the family name and its implication of how their family will be labeled or constructed by members of the society. In line with this, Agaba (2013) posits that the increase in the rate of rape cases in Nigeria may not be unconnected with the culture of "brotherliness, spirit of forgiveness and non-placement of priority and prominence" in the reportage of rape cases. A woman who caught her husband sleeping with her daughter was forced to 'die the case' because of family pressure. She was a step mother. She opined that:

I sent my daughter to go up into their room and bring a cloth to cover my little boy, who was sick. I was waiting for her to return with the cloth so I could cover her brother, but I didn't see her, I took my torch and went upstairs to see why it was taking her too long. To my greatest surprise, my husband approached me at the door naked; evading him I also saw my daughter naked on the floor. She was about telling me what happened before my husband slapped her. I couldn't hold it so I screamed and started shouting. His other children came out and told me not to make noise about it so I wouldn't disgrace their father. These days when I come across him or his children, they keep threatening me. His children forced me to take the sum of N50,000 and sign an affidavit to not press charges. (The Punch, Saturday, October 10, 2015: 26)

These findings align with previous studies on crime reporting behavior in nigeria. For Instance, Ayodele and Aderinto (2014) found that lack of public 
confidence in law enforcement agencies may prevent people from reporting to the police. In another study, they (Ayodele and Aderinto, 2014) note that the nature of crime determines whether the victim will report or not. This is dependent on whether the victimization is considered severe or mild. Furthermore, Ayodele (2017) stressed that the economic and socio-cultural factors such as familiarity, taboos, and poverty affect reporting behavior of victims of crime in Lagos state.

\section{Rape Reportage according to Region}

Northern region recorded the lowest reportage of rape cases with a total of twenty-one cases for the duration of five years, which is about $6 \%$ of the total reported rape cases by the two selected newspapers. However, the SouthWestern region recorded the highest number of reported rape cases with a total of 219 cases, which is about $66 \%$ of the total reported cases by the two selected newspapers. This thus indicates that rape is more likely to occur twice as much in the South-Western region of Nigeria than any other region in the country. One of the reasons may the fact the most of the media houses have their headquarters in the south west. This gives the southwest dominance in news coverage and reporting than any other region in the country. Another reason is that most states in the southwest have many human rights groups who fight for justice on behalf of rape victims.

Table 2: Region with the most reported rape cases in Nigeria

\begin{tabular}{|l|l|l|}
\hline Regions & Frequency & Percentage\% \\
\hline South-East & 22 & 6.6 \\
\hline South-West & 219 & 66.2 \\
\hline South-South & 42 & 12.6 \\
\hline North-Central & 27 & 8.1 \\
\hline North & 21 & 6.3 \\
\hline Total & 331 & 100.0 \\
\hline
\end{tabular}

Most of the states in the southwest have passed the Child Right Act (CRA); this makes it possible for crimes against children such as rape to be easily prosecuted and the perpetrators punished. However, in the North, majority of the states have not passed the CRA, thus there is a possibility that violations of children go unnoticed or unreported. Having said these, southwest is seen as the commercial backbone of the country because of the presence of Lagos, as a result they attract all kinds of people from different criminal background and cultures, this influx of people will most likely lead to increase in criminal behaviour. From the foregoing, frequency in the reportage of rape by the media in various states or region might be related to epidemiological reports. That is, the more the violence or rape is reported to the police, the more frequently it was to appear in newspapers and vice versa. 


\section{Framing Dynamics in Rape Reportage}

Four major frames were used when reporting rape cases mainly episodic frame, morality frame, human interest frame and attribution frame. Episodic frame recorded a total of forty (40), which is about $15 \%$ of all reported rape cases in the selected newspapers. This implies that some rape cases were reported around specific instances and individuals. This type of frame focused solely on the personality, disposition or the state of motivation of the people in question. Elaborating on this, specific themes that postulated episodic frame includes titles such as: "Man arraigned for rape", "Rape on the rise in Kano", Police arrest four for robbery, rape in Ogun". These above captions only focused on the surface value of the reports without any in-depth information about the stories contained in the report.

Morality frame recorded a total of seventy-two 72 , which is about $22 \%$ of the total frames employed by the two selected newspapers during reportage. Morality frames laid more emphasis on the moral or religious milieu of an issue or event. Moral frames were mostly used to keep the norms and values of the society. Elaborating on this, specific themes that postulated morality frame includes titles such as: "Randy man 46, rapes 5 years old girl", "man defiles 11-year old daughter", "Pastor defiles 14-year old in his church", "65-year old man rapes, impregnates own teenage daughter" "Perverts in the house of God". These above titles tried to bring to mind of the audience the abomination of not just the act but also the nature of the actors.

The human interest frame was the most used frame when reporting rape cases by the two selected newspapers; this is because it recorded a total of two hundred and five (205) which is about $62 \%$ of all reported rape cases for the past five years. The rationale behind the usage of human interest frame was to appeal to the emotional part of the audience to be able to relate with the victim on a personal level. Elaborating on this, several titles that tried to propagate human interest include titles such as: "13-year old pregnant for four old men", "woman forced to apologise to her rapist", "beastly soldier rapes boy 16", "Cripple repeatedly abused nine-year old boy". The titles above have been specially written to draw and retain the attention of the readers on the information being passed. The idea of human interest frame is to exaggerate the problem so as to draw empathy from the wider public. This frame can be very instrumental in bringing rape to the notice of the public and also help to create a negative attitude towards it.

Attribution of responsibility frame on the other hand, recorded the least used frame among the two selected newspapers for the period of five years. They recorded a total of fourteen (14) which is about $4 \%$ of the entire frames used by the selected newspapers. Attribution of responsibility frame presents issues in such a way as to ascribe the cause or solution of a problem to somebody, government or a thing external to the individual. Elaborating on this, some titles which postulated attribution frame includes: "I raped my 
daughter to get a job", "Alcohol made me rape, rob 82-year old woman", "I raped my girlfriend to enjoy Valentine's Day". As indicated above, the above news headlines show that most of the accused rapists were not to be entirely blamed for the rape. This therefore tends to further re-instill a common belief that most of the victims are to be blamed for their predicament and that most rapists are not totally at fault for their actions. Such headlines attribute the cause of rape to other factors seemingly beyond the control of the rapist.

\section{Conclusion}

The study examined the coverage of rape and its representation in two selected newspapers in Nigeria. The study was inspired by the phenomenal coverage of rape within the period investigated due to the fact that reporting rape in the media was uncommon. Rape remain an under reported crime in the country with only a total of 331 cases reported within the period (2012 to 2016) by the two selected newspapers. The study discovered that factors such as; stigmatization, fear of the assailant or rapist, religion, family ties, inability to access security personnel and/or media correspondents were among the factors responsible to low reporting of rape and coverage by the media. In the data examined, the Southwestern part of the country enjoyed best coverage when compared to other six regions of the country. A plausible explanation is the level of enlightenment within this region relative to others. It is also important that the headquarters of 70percent of Nigeria media houses are located within this region which accounts for this disproportionate coverage of rape. Despite this rape cases in urban area are more likely to be covered by the media than those that occurred in rural or remote areas. Among the four frames used by the dailies, the dominant frame employed was human interest frame. Both newspapers deployed to draw empathy from the public as well as retain the attention of their readers. This type of frame also elicits reaction from policymakers and law enforcement agencies.

In most cases, the two newspapers placed most of their stories on rape inside their newspapers than at the cover pages which shows how serious they view the crime. Also in reporting the crime, some important details such as how the rape was perpetuated, the region, age and relationship between the victim and offender, duration of the act etc. that would help give a wider spectrum of the act as well as further educate the public are omitted. In some cases, the newspapers ended up re-victimizing the rape victims by ascribing or making them appear responsible for their trauma.

Arising from the findings, there is a need for the media to also employ more diagnostic and prognostic frames. By diagnostic frame, Nigeria newspapers need to focus more on identifying the problem, attributing blame and causality. The media cannot stop at the level of diagnostic frames but must proffer solutions (prognostic frame), on how to better resettle rape victims as well as reduce the crime itself. Such a frame would help improve 
the criminal justice system as well as give voice and agency to the victims of rape. Since social construction is central to rape reportage, the media possesses enormous power to construct reality through appropriate representations of the raped, their victims by defining reality through appropriate portrayal to engender action against rape and inform policies towards protecting the victims of rape and granting them justice.

\section{References}

Ayodele, O. Johnson and Aderinto, A.A. (2014) Public Confidence in the Police and Crime Reporting Practices of Victims in Lagos Nigeria: A Mixed Methods Study. International Journal of Criminal Justice Sciences (IJCJS), 9(1): 46-63.

Ayodele, O.J. and Aderinto, A.A. (2014) Nature of Crime and Crime Reporting of Victims in Lagos, Nigeria. International Journal of Criminology and Sociological Theory, 7(1): 1-14.

Ayodele, O.J. (2017) Reasons for Victims' Nonreporting Practices in Lagos, Nigeria: A Qualitative Study. Victims \& Offenders, DOI: 10.1080/15564886.2017.1280107.

Ajayi, O. (2017) 4 men rape 11-year old girl in Ibadan. https://www.vanguardngr.com/2017/02/4-men-rape-11-yr-old-girl-ibadan/accessed on 15-06-2018.

Akinade, E.A., Adewuyi, T.D.O., Sulaiman, A.A. (2010) Socio-legal factors that influence the perpetuation of rape in Nigeria. Procedia - Social and Behavioral Sciences, 5: 1760-1764.

Agaba, A.O. (2013) "Prosecuting rape cases in the Nigeria legal system." In Afolabi, S.O. (Ed.). Justice system in Nigeria: An X-ray, Ibadan: Standard Publishers.

Berger, P.L. and Thomas Luckmann (1966) The Social Construction of Reality: A Treatise in the Sociology of Knowledge. Garden City, NY: Doubleday.

Buddie, A.M. and Arthur, G.M. (2001) "Beyond Rape Myths: A More Complex View of Perceptions of Rape Victims." Sex Roles, 45: 139-160.

Byerly, C. and Ross, K. (2006) Women \& Media. Blackwell Publishing, U.S.A.

Cahill, A.J. (2000) Foucault, rape and the construction of the feminine body. Hypatia, 15(1): 43-63.

Carlyle, K. et al. (2008) 'Newspaper Coverage of Intimate Partner Violence: Skewing Representations of Risk.' Journal of communication, 58(1): 168186. Available at http//www. blackwell-synergy.com/doi/pdf, [Accessed on February 15, 2017].

Carter, C. (1998) News, Gender and Power. In Carter, C., Branston, G. and Allan, S. (Eds.). New York: Routledge. 
Chika, I.S. (2011) Legalization of marital rape in Nigeria: a gross violation of women's health and reproductive rights. Journal of Social Welfare and Family Law. 33(1): 39-46.

Chong, D. and Druckman, J. (2007) 'A Theory of Framing and Opinion Formation in Competitive Elite Environments.' Journal of communication, 57(1): 99-118. Available at http//www. blackwell-synergy. Com/doi/pdf. [Accessed on February 4, 2017].

Chong, D. \& Druckman, J.N. (2007) Framing Theory. Annual Review of Political Science, 10(1): 103-126.

Classen, C., Palesh, O. and Aggarwal, R. (2005) Sexual revictimisation: a review of the empirical literature. Trauma Violence \& Abuse, 6(2): 103129.

Clemente, M. and Gabbioneta, C. (2017) How Does the Media Frame Corporate Scandals? The Case of German Newspapers and the Volkswagen Diesel Scandal. Journal of Management Inquiry, 1-16 DOI: $10.1177 / 1056492616689304$.

Daru, P.H., Osagie, E.O., Pam, I.C., Silas, O.A., Ekwempu, C.C. (2011) Analysis of the cases of rape as seen at the Jos University Teaching Hospital, North central Nigeria. Nigeria Journal of Clinical Practice, 14(1): 47-51.

Entman, R. (2007) 'Framing bias: Media in the distribution of power.' Journal of communication, 57(1). Available at http//www.blackwell-synergy. Com/doi/pdf[Accessed on February 6, 2017].

Gitlin, T. (1980) The whole world is watching: mass media in the making and unmaking of the New Left. Berkeley: University of California Press.

Hurbutt (2011) An examination of journalistic standards in media coverage. (unpublished thesis).

Iyengar, S. \& Reeves, R. (1997) Do the media govern? Politicians, voters and reporters in America. Califonia: Sage publications Inc, Thousand Oaks.

Jones, L., David Finkelhor and Jessica Beckwith (2010) "Protecting victims' identities in press coverage of child victimization." Journalism. 11: 347367.

Korn, A. (2004) Israeli press and the war against terrorism: the construction of the "liquidation policy". Crime, law \& social change, 41(3): 209-234.

Marshall, L. (2004) Media Culpability in the Continuum of Violence against Women: Available at http://www.countercurrents.org/gender-marshall300904.htm: [Accessed onJanuary 14, 2017].

Mc Manus, J. and Dorfman, L. (2002) 'Youth Violence Stories focus on Events, Not Causes.' Newspaper Research Journal, 23(4).

Mushau, R. (2013) Between justice system and rape epidemic. The Guardian newspapers, Sunday, November 3, 2013, p. 53. 
Nwabueze and Oduah (2014) Media Re-victimization of Rape Victims in a Shame Culture: Exploring the Framing and Representation of Rape Cases in Nigerian Dailies. Global Media Journal, 13(24): 5.

Oduah, F.M. (2014) Media Coverage of Rape Cases in Nigeria. An unpublished M.Sc. Dissertation, Department of Mass Communication, Anambra State University, Igbariam Campus.

Quarshie, E.N.B., Joseph Osafo, Charity S. Akotia, Jennifer Peprah \& Johnny Andoh-Arthur (2017) Some Epidemiological Characteristics of Perpetrators and Victims of Incest in Contemporary Ghana: Analysis of Media Reports. Journal of Child Sexual Abuse, 26(2): 121-139.

Quarshie Emmanuel Nii-Boye, Priscilla Ayebea Davies, Mawuena Ivanna Adzoa Badasu, Theophilus Tagoe, Pearl Ama Otoo \& Patricia Opoku Afriyie (2017) Multiple perpetrator rape in Ghana: offenders, victims and offence characteristics. Journal of Sexual Aggression: An international, interdisciplinary forum for research, theory and practice, 24(1): 125-141.

Rape (2012) Rape [online]. Available www:http://www.soc.ucsb.edu/sexinfo/article/rape (Accessed 11 January 2017).

Scheufele, D.A. (1999) Framing as a theory of media effects. Journal of communication, (ejournal), 49(1): 103-122. Available through EBSCO Host website: http://web.ebscohost.com.ezproxy.ukzn.ac.za:2035/ehost/detail?sid=ad911438-eccd4-9869-bd73-.

Shen, F. (2004) 'Chronic Accessibility and Individual Cognitions: Examining the effects of Message Frames in political Advertisements.' Journal of Communication, 30(1): 123-137. Available at http//www.blackwellsynergy.com/doi/pdf [Accessed on January 28, 2017].

Shen, F. (2004) "Effects of News Frames and Schemas on Individuals' Issue Interpretations and Attitudes." Journalism and Mass Communication, Quarterly 81(2): 400-416.

Simpson, Roger and William Cote (2006) Covering Violence: A guide to ethical reporting about victims and trauma. New York: Columbia University Press.

Steeves, H. (1997) Gender violence and The Press: The St. Kizito story. Ohio University, Ohio.

Steyn, E. (2005)Victimisation of Rape Victims in the Criminal Justice System. A Project work, Department of Safety and Security Management, Tshwane University of Technology.

The Daily Sun (2013) Three men rape a seven year old girl. December 19, 2013.

The Daily Sun (2014) Seventeen year old girl abducted and raped while returning from school by a gang of three. January 2014.

The Daily Sun (2013) A virgin school girl raped by a gang of three. October 31, 2013. 
The Daily Sun (2011) Police officer dismissed for raping two year old girl. November 6, 2011.

The Guardian (2013) Twenty nine year old arraigned for armed robbery and rape. January 6, 2013.

The Punch (2013) Driver rapes 15-year old housemaid, blames the devil. April 10, 2013. Written by Eniola Akinkuotu.

The Vanguard (2013) A Pastor rapes three under age pupils. October 25, 2013.

Tusher, C.P. (2007) Revictimization: Advancing the theory and methods. Dissertation, Georgia state university. Available at http://scholarworks.gsu.edu/psych_diss/28. Accessed on February 11, 2017.

United Nation Fund for Population (2007) Ending Widespread Violence Against Women. Available at $<$ http://www.unfpa.org/gender/violence.ht$\mathrm{m}>$ [Accessed on February 12, 2017].

Usman, E. (2017) Four year old girl gang-raped to death for turning down miscreants love advances. https://www.vanguardngr.com/2017/07/14-yrold-girl-gang-raped-death-turning-miscreants-love-advances/ accessed on 15-06-2018.

Van Dijk, T.A. (1988) News analysis: case studies of international and national news in the press. Hillsdale, NJ: L. Erlbaum.

Weaver, H.D. (2007) 'Thoughts on agenda setting, framing, and priming. Journal of Communication, 57(1): 142-147. Available at http//www. blackwell-synergy. Com/doi/pdf [Accessed on February 4, 2017].

Onyejekwe, C.J. (2008) Nigeria: The Dominance of Rape. Journal of International Women's Studies, 10(1): 48-63. 